\title{
aCGH Analysis to Estimate Genetic Variations among Domesticated Chickens
}

\author{
Tomoyoshi Komiyama, ${ }^{1}$ Mengjie Lin, ${ }^{2}$ and Atsushi Ogura ${ }^{3}$ \\ ${ }^{1}$ Department of Clinical Pharmacology, Tokai University School of Medicine, 143 Shimokasuya, Isehara, Kanagawa 259-1193, Japan \\ ${ }^{2}$ Department of Biology, Ochanomizu University, Tokyo 112-0012, Japan \\ ${ }^{3}$ Nagahama Institute of Bio-Science and Technology, Nagahama, Shiga 526-0829, Japan
}

Correspondence should be addressed to Tomoyoshi Komiyama; komiyama@tokai-u.jp and Atsushi Ogura; aogu@whelix.info

Received 11 April 2016; Accepted 20 June 2016

Academic Editor: Yi-Ping Liu

Copyright (C) 2016 Tomoyoshi Komiyama et al. This is an open access article distributed under the Creative Commons Attribution License, which permits unrestricted use, distribution, and reproduction in any medium, provided the original work is properly cited.

\begin{abstract}
Chickens have been familiar to humans since ancient times and have been used not only for culinary purposes but also for cultural purposes including ritual ceremonies and traditional entertainment. The various chicken breeds developed for these purposes often display distinct morphological and/or behavioural traits. For example, the Japanese Shamo is larger and more aggressive than other domesticated chickens, reflecting its role as a fighting cock breed, whereas Japanese Naganakidori breeds, which have long-crowing behaviour, were bred instead for their entertaining and aesthetic qualities. However, the genetic backgrounds of these distinct morphological and behavioural traits remain unclear. Therefore, the question arises as to which genomic regions in these chickens were acted upon by selective pressures through breeding. We compared the entire genomes of six chicken breeds domesticated for various cultural purposes by utilizing array comparative genomic hybridization. From these analyses, we identified 782 regions that underwent insertions, deletions, or mutations, representing man-made selection pressure in these chickens. Furthermore, we found that a number of genes diversified in domesticated chickens bred for cultural or entertainment purposes were different from those diversified in chickens bred for food, such as broilers and layers.
\end{abstract}

\section{Introduction}

Today, many chicken breeds have been kept worldwide as laying hens and for poultry, as well as for other purposes or as pets. However, chicken domestication extends back to antiquity, when the chicken was domesticated to provide meat and eggs, which are valuable culinary items [1-3], and to perform various other tasks. For example, as chickens crow loudly at dawn, they were used for reporting the time. In some regions and societies, the chicken was considered a mysterious animal with a beautiful appearance and song, and humans enthusiastically bred them to suit a more ritual role. In Japan, fighting cocks and long-crowing chickens are typical examples of chickens that have been bred for entertainment and aesthetics. Past studies regarding the molecular evolution of these chickens in Asia revealed that cultural domestication has imposed a strong artificial selective pressure [4]. Moreover, phylogenetic analyses of these chickens clarified that their domestication process was tightly connected to Japanese culture $[5,6]$.

Thus, people have improved the desirable characteristics of chickens to make use of them in daily life. The origin of all modern domesticated chicken breeds is considered to be the red junglefowl (Gallus gallus), one of four species of wild fowl indigenous to Southern China, Southeast Asia, and parts of Southwest Asia [7]. The domestication of chickens is believed to have started in the Indus Valley region around 2000 BC [8]; however, based on archaeological evidence West and Zhou [9] argued that much earlier domestication arose in mainland China around $6000 \mathrm{BC}$. The genetic changes that accumulated during the domestication process of broilers and layers are an important target for population genetics and molecular evolution as well as for animal science and stockbreeding. To study the domestication of chickens for cultural purposes rather than for food purposes is important not only for clarifying the genomic backgrounds of "culturally domesticated" 
chickens but also for elucidating differences in genomic changes and in artificial selection among various breeds for diverse purposes.

In this study, we focused on genetic diversity among culturally domesticated chickens in Japan, which contains many domesticated chicken breeds. Each of these breeds is characterized by a different temperament, physical shape, and behaviour, attained through specialized breeding and artificial selection. For example, fighting cocks, commonly called Shamo, have been bred solely for the purpose of cockfighting. Likewise, long-crowing chickens, commonly known as Naganakidori, have been specifically bred to acquire an exceptionally long crow of over 15 seconds [5]. Similarly, the Chabo and Minohikidori were bred for ornamental purposes through a special process [10].

Japanese domesticated chickens are excellent models for studying the influence of human culture on animal domestication and breeding. We previously found that numerous intense artificial selection events occurred before the divergence of Japanese chickens from ancestral fighting cocks, as suggested by the remarkably different phenotypes of Japanese ornamental chickens $[5,6,10,11]$. Further studies of domesticated and wild chickens in Asia using mtDNA and nuclear DNA sequences as well as the domestication process of modern chickens have remained unexplored. In our molecular evolutionary studies based on the mitochondrial D-loop region, the fighting cock breed Shamo was found to have first diverged from red junglefowl, G. gallus, and then later converged to form clusters, long-crowing chicken breeds Koeyoshi and Tomaru group and then the Shamo, Katsurachabo, Satsumadori, and Koshamo group (Figure 1) [6]. These Japanese-bred domesticated chickens are descendant of $G$. gallus gallus and can be interbred.

In 2004, Wong et al. reported their study of wholegenome single nucleotide polymorphisms (SNPs) to uncover genetic variations in chicken. Furthermore, Muir et al. [12] reported the significant absence of rare alleles in commercial breeds by genome-wide SNP assessment. Genome-wide surveys for SNPs and quantitative trait loci related to chicken domestication have been conducted by several other groups $[13,14]$ but no studies examined differences among breed characteristics. In recent research, Rubin et al. [15] expanded this approach by resequencing the whole genome to reveal loci under selection during the domestication of chickens for food; however, they found little evidence that selection for loss-of-function mutations had a prominent role in chicken domestication. Only a few studies have shed light on the genetic variations in various chickens $[16,17]$. There are several other studies focusing on domestication itself, but none of this research has focused on the domestication aimed for cultural purposes [18-21].

Against this background, the objective of this study is to understand the process of the cultural domestication of chickens by identifying and characterizing the genetic factors that have contributed to the phenotypic changes from ancestral wild fowl (i.e., red junglefowl) to domesticated chickens, such as behaviour, body size, and comb type. We examined chickens bred for fighting and as ornamentals by array comparative genomic hybridization (aCGH) to identify

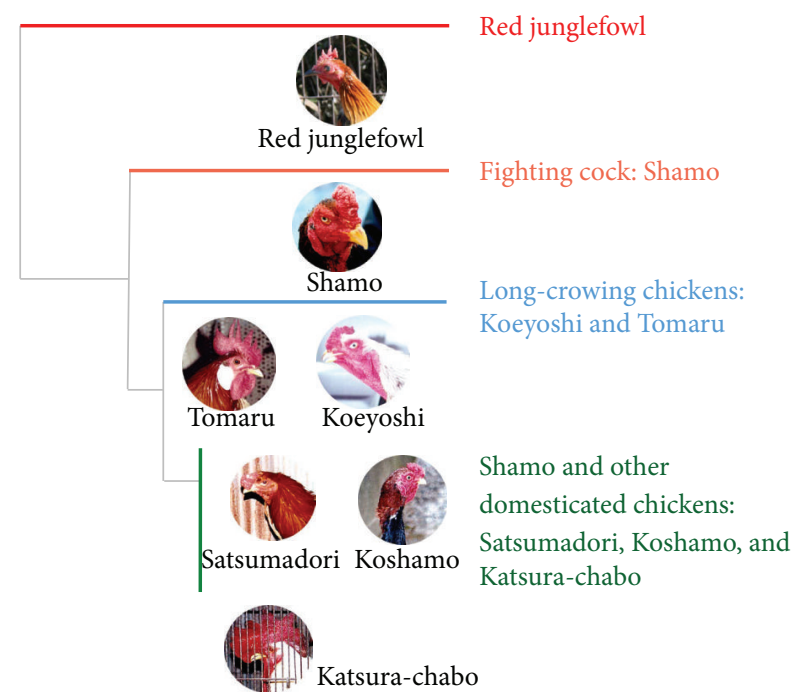

Figure 1: Phylogenetic tree of wild and culturally domesticated chickens used in this study. The phylogenetic tree was drawn using nucleotide sequences of mitochondrial D-loop regions of our previous result [6].

genes highly specific to these breeds. The aCGH is a method of identifying genetic variations among samples by utilizing genomic DNA and a microarray. Our aCGH is designed to investigate genetic variations within groups of culturally domesticated chickens.

\section{Materials and Methods}

2.1. Sample Collection. We obtained a total of 7 samples, fighting cocks (Shamo 49 and Satsumadori 31) [6], long-crowing chickens (Naganakidori: Tomaru 203 and Koeyoshi 27), other ornamental chickens (Katsura-chabo 20 and Koshamo 13), and one Yakei (G. gallus 222), from the Bird Center of Kurume in Fukuoka Prefecture. These domesticated chickens had been collected in our previous studies. In addition, these numbers are linked to our previous researches $[4-6,11]$.

2.2. Probe Design and aCGH. A total of 59,801 probes, representing 17934 genes, were designed using the Chicken HD probe set in eArray (Agilent Technologies, Santa Clara, CA, USA). Two sets of $8 \times 60 \mathrm{~K}$ arrays were used for the aCGH experiments. A genomic DNA labelling kit was used to label gDNAs that were hybridized to the chicken CGH array. The Yakei was used as a reference sample, and six culturally domesticated chickens were used in aCGH experiments. Dye-swap experiments were also performed.

2.3. Statistical Analysis. We removed probes that were flagged as either "not uniform" or "population outlier." We then removed control probes and unreliable data that were inconsistent with the results of the dye-swap experiments and obtained 47,308 probes out of 59,801 probes. We then classified probes into three categories: (1) probes with intensities less than $0.5 \mathrm{x}$ median of all probes; (2) probes with intensities between 0.5 and $2.0 \mathrm{x}$ of the median of all probes; and 

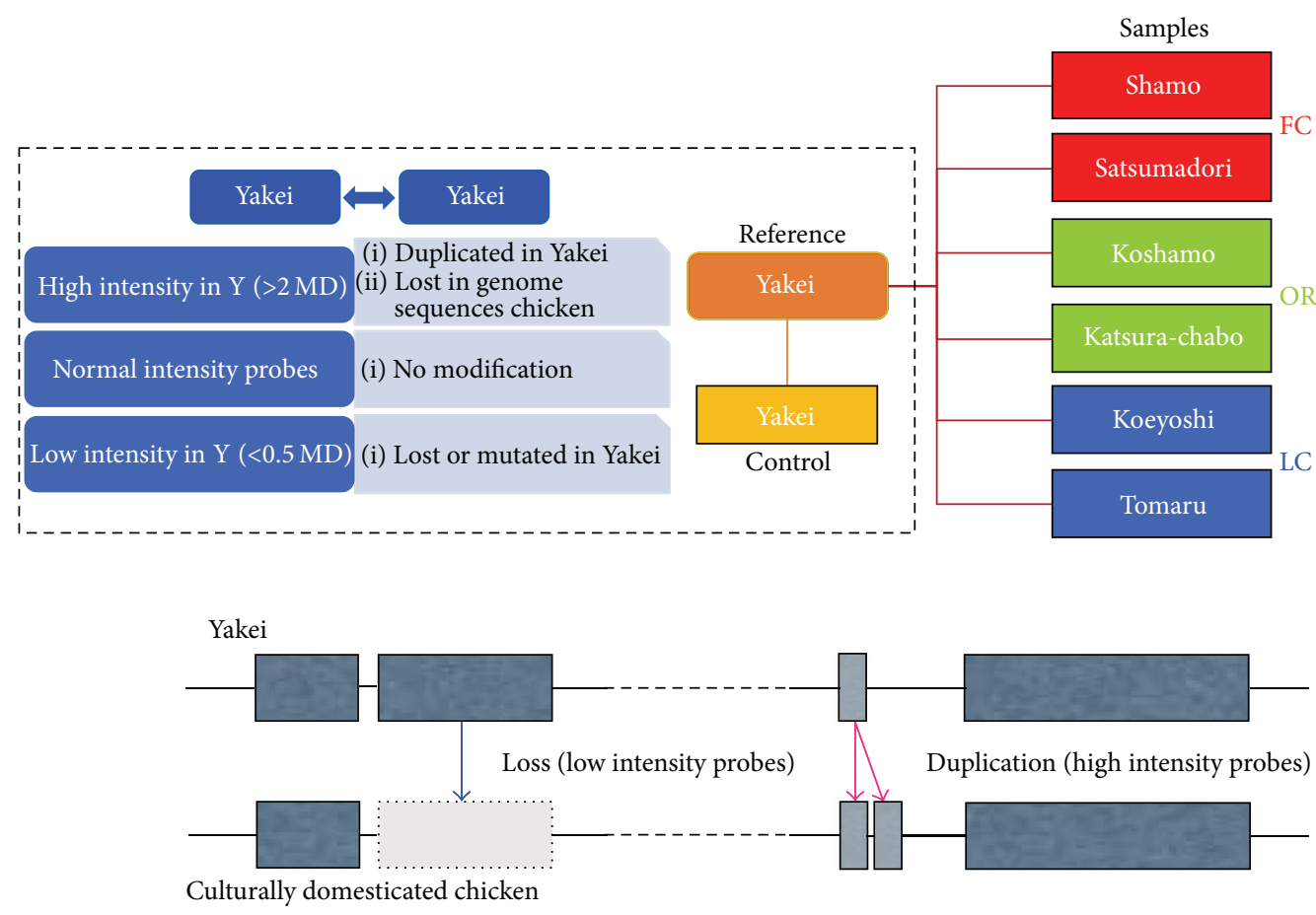

FIGURE 2: Experimental design and analytical scheme. To unveil genetic variations between Yakei (Y) and genome sequenced chicken (GSC). In the aCGH experiments, hybridizations were performed using $\mathrm{Y}$ on a custom microarray in which probes were designed from GSC. To clarify genetic variations in culturally domesticated chickens Y (reference) and 6 domesticated chickens (sample) were used for aCGH experiments.

(3) probes with intensities larger than $2.0 \mathrm{x}$ of the median of all probes. One-way ANOVA was performed under the following conditions: $p$ value computation; Asymptotic Multiple Testing Correction; Benjamini-Hochberg FDR; and Number of Permutations, 100. We ultimately obtained 6,385 statistically significant probes with a corrected $p$ value of 0.05 . Fold change: we first collected probes that matched both the probes that were not changed in the Yakei $(42,175$ probes) and the probes that were selected by ANOVA (6,385 probes). We then extracted probes in which the probe intensity was either $2.0 \mathrm{x}$ larger than that in the Yakei or $0.5 \mathrm{x}$ less than that in the Yakei in each strain.

\section{Results}

3.1. aCGH Analysis to Estimate Genetic Variations among Culturally Domesticated Chickens. To understand genetic variations underlying cultural domestication of chickens, aCGH analysis has been performed employing a microarray designed from the genome of the classic genome-sequenced domesticated chicken (GSC) and hybridization experiments using six culturally domesticated chickens, comprising two fighting cock breeds, two long-crowing chickens breeds, and two ornamental chickens breeds, as well as the red junglefowl, as the reference genomic DNA. We used the eArray (Agilent Technologies, Santa Clara, California) for probe design and made two array slides with $8 \times 60 \mathrm{~K}$ probes that would cover all the chromosomes of the chickens. We then performed two-colour hybridization with dye-swap using gDNA from six culturally domesticated chickens as well as from Yakei as a control (Figure 2). Schematic workflow of this study is shown in Figure 3.

To estimate genetic variations among culturally domesticated chickens, we first extracted the genetic variations derived from human breeding. We then compared the array results of the Yakei (reference) and the GSC (control) (Figures 2 and 3). As our aCGH is designed from the GSC, it is essential to distinguish the genetic variation during cultural domestication (one Yakei to six domesticated chickens) from the genetic variation that has already been accumulated in the branch of GSC to Yakei. We first removed unreliable results from the array data using GeneSpring and obtained 47,193 probes, among which 42,114 probes were considered to be not diversified from those of the GSC. Among the remaining 5,079 probes, 3,549 had higher intensity than the median intensity of all probes, which would be accounted for by one of the following three explanations: (1) corresponding genomic regions were lost or highly mutated in the Yakei lineage, (2) corresponding genomic regions were lost or highly mutated in the GSC, or (3) corresponding genomic regions were duplicated in the GSC (Figure 4). To distinguish between these possibilities for each probe, we examined duplicated regions or corresponding genomic regions against the rest of the genome sequence using electronic polymerase chain reaction (PCR) and found that 1,522 regions had been duplicated in the GSC and that the remaining probes had not undergone any duplication events. The remaining 1,530 probes out of the 5,079 diversified probes had more than 


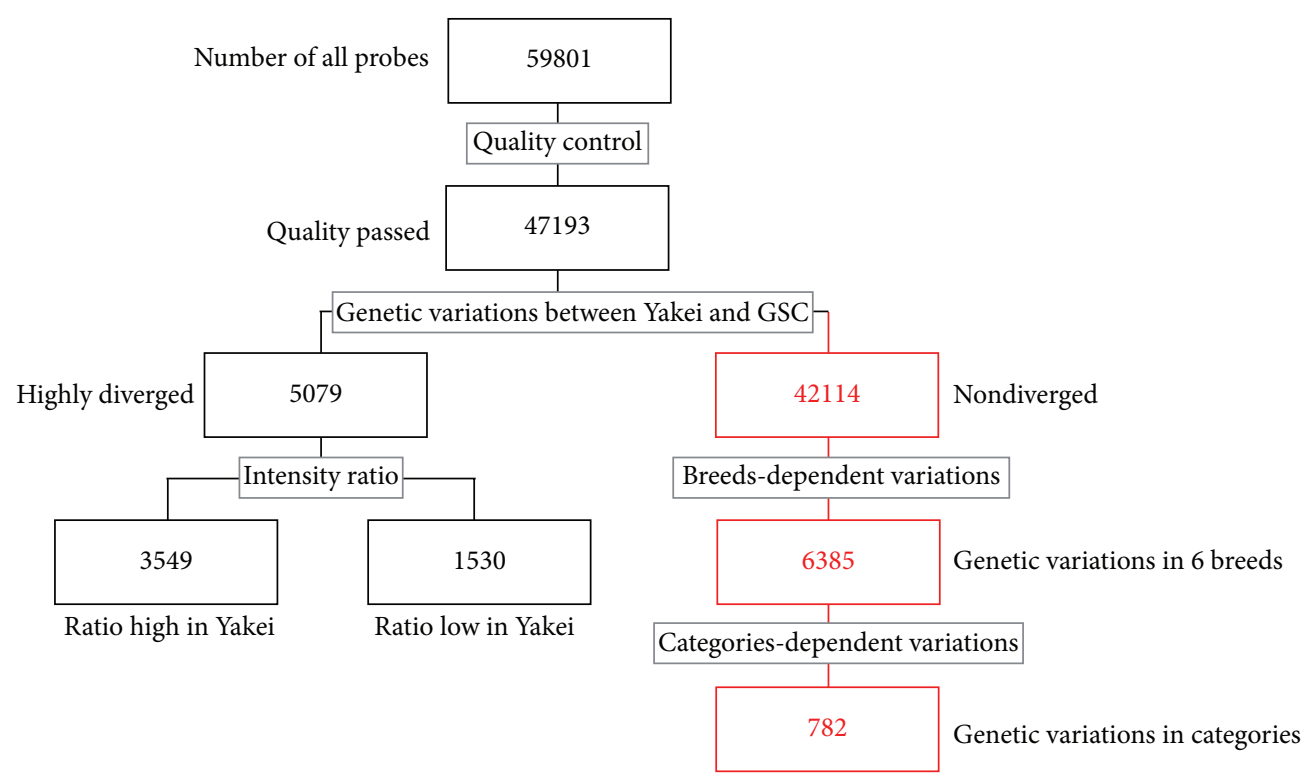

FIGURE 3: Scheme for the experiment and analysis. Figures indicate the number of probes after analyses shown in grey boxes.

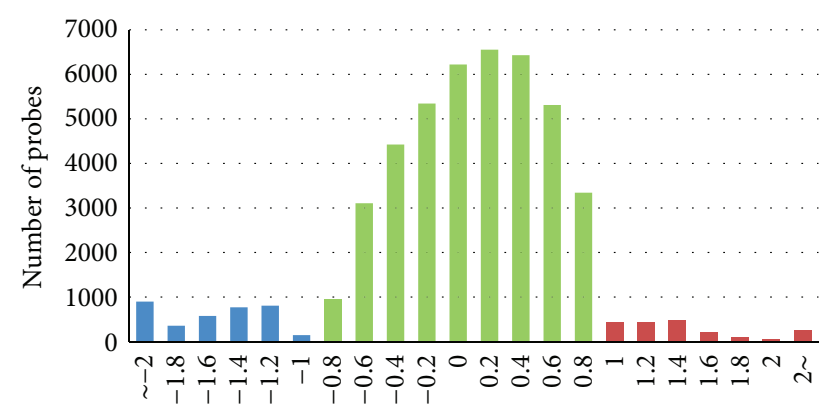

Figure 4: Overall genetic variations in culturally domesticated chickens. Regions with relative intensity between samples and the control less than -1.0 were categorized as "lost or mutated candidates in Yakei (Y)" (blue colour). Regions with relative intensity between samples and the control larger than 1.0 were categorized as "duplicated candidates in Yakei (Y)" (red colour). Nondiverged probes indicated in green colour. The $y$-axis represents fold changes on a $\log 2$ scale.

double the median intensity of all probes, implying that those regions might be duplicated in the Yakei lineage. These results suggest that $10.8 \%(5,079 / 47,193)$ of the regions in the chicken genome have been altered in the branch of the GSC and Yakei (Figure 4).

To investigate genetic variations in culturally domesticated chickens, we analysed aCGH data for Yakei and six such breeds: Shamo (fighting cock), Satsumadori (fighting cock), Tomaru (long-crowing), Koeyoshi (long-crowing), Katsurachabo (ornamental), and Koshamo (ornamental) (Figure 2). To estimate the genetic alteration in these six breeds, we utilized a total of 42,114 probes for further analysis that were not diversified in GSC to Yakei branch (Figure 3). Next, 6,385 of the 42,114 probes were further selected as candidate regions for genetic diversification in any of culturally domesticated chickens by one-way ANOVA. The gene set enrichment analysis of 6,385 probes was then performed. The gene ontology terms associated with "cell periphery" and "signaling processes" were significantly overrepresented in these probes. In all breeds except the Shamo, the number of lost or mutated candidates exceeded those of duplicated candidates, especially in Koeyoshi. Concerning domesticated categoryspecific variations, 782 probes have been found in fighting cocks, long-crowing chickens, and ornamental chickens that differ by a fold-change threshold of 2.0 (Figure 4). These results indicated that the fighting cocks tended to duplicate genes during domestication for the purpose of combat, as opposed with the ornamental (OR) and long-crowing (LC) chickens, which tended to have a higher proportion of mutated or lost genes. In addition, two breeds of the fighting cock (Shamo and Satsumadori) had fewer genes in common (blue) compared with the breeds in other categories (Figure 5), because the fighting cock group was composed of relatively distant lineages as shown in Figure 1. To validate the estimation of genomic variations, we amplified 26 among 782 candidates by PCR based on the primer designed from sequence obtained from GSC. As a result, 16 out of 26 regions were confirmed to be mutated in the corresponding chickens (see Table 1) (Supplementary Data 1 in Supplementary Material available online at http://dx.doi.org/10.1155/2016/1794329).

\subsection{Genes Subjected to Selection Pressures under Cultural} Domestication. Next, we searched for candidate genes that may have been subjected to selection pressures under cultural domestication. We found that even though most candidates were lost regions, the Shamo breed and Naganakidori type breeds possess a large number of candidate duplicated regions, most of which are related to the nervous system and membrane proteins. Therefore, regions duplicated in Shamo are related to muscle development genes, such as MYH1 and 

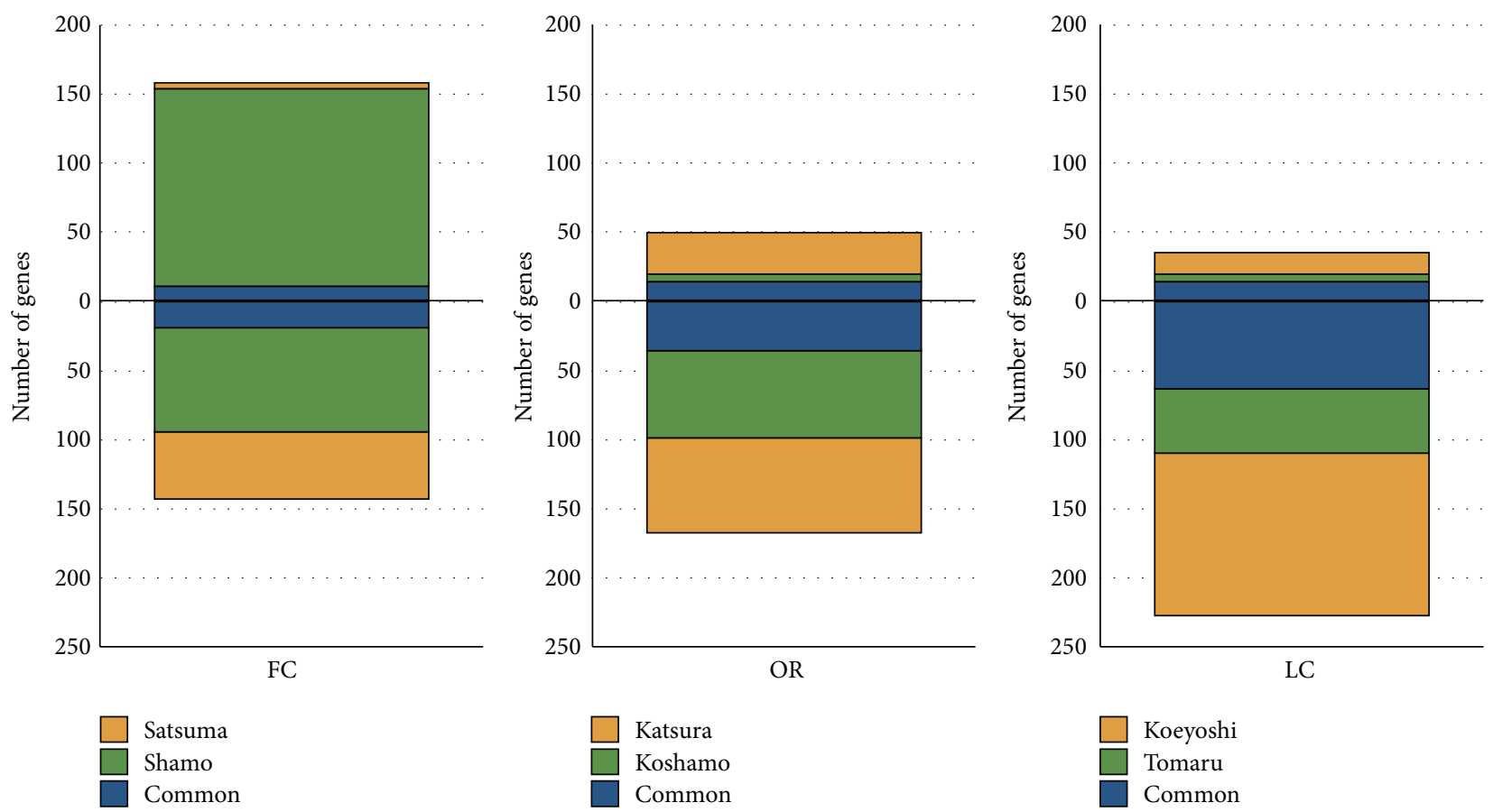

FIGURE 5: Duplicated genes and mutated or lost genes in the fighting cocks (FC), ornamental chickens (OR), and long-crowing chickens (LC). The upper half indicates the number of duplicated genes in the categories; colour indicates common or strain specific genes in each chicken breed. The lower half indicates the number of lost or mutated genes in the categories.

TABLE 1: Enriched GO categories in the genes for human selection pressures in the domesticated chickens.

\begin{tabular}{lccc}
\hline GO term & $\begin{array}{c}\text { Corrected } \\
p \text { value }\end{array}$ & $\begin{array}{c}\text { Count in } \\
\text { selection }\end{array}$ & $\begin{array}{c}\text { Count in } \\
\text { total }\end{array}$ \\
\hline Cell periphery & 0.001 & 204 & 750 \\
Plasma membrane & 0.001 & 204 & 712 \\
Membrane & 0.001 & 559 & 1,810 \\
Membrane part & 0.001 & 313 & 1,244 \\
Signaling process & 0.003 & 142 & 1,048 \\
Signal transmission & 0.003 & 3.5 & 1,048 \\
Synapse & 0.004 & 41 & 112 \\
Plasma membrane part & 0.006 & 27 & 420 \\
\hline
\end{tabular}

GO: gene ontology.

MYH7B [22-24]. We have also found genes as candidates, namely, IGF-2, Robol, and DCX [25-35]. These regions might have undergone human selection pressure for fighting ability. We have validated that IGF1, MYH1, and $M Y H 7 B$ genes were duplicated in different chromosomes that might affect gene expression efficiency at the level of muscular development.

The Koeyoshi, long-crowing chicken breed, has lost many genes common to other cultural domesticated chickens. In addition, Katsura-chabo was revealed to possess interesting genes. In particular, PIT1 genes were associated with chicken growth traits [36-38]. Compared to wild fowl, domesticated chickens are smaller, and the male grows to only approximately 1.0 kilograms in weight [10]. Koeyoshi and Chabo also have undergone strong artificial selection by ancient humans.
Although gene expression analyses for differences among commercially domesticated chickens are intensively performed [21, 39-41], none of the above genes have been reported. Therefore, these genes are thought to be related to cultural domestication rather than domestication for commercial purposes.

3.3. Comparison of Genetic Changes between Cultural Domestication and Food Domestication. aCGH analysis allowed us to obtain 782 probe candidates for cultural domestication in long-crowing, fighting, and ornamental breeding lines (Figure 3 ). We then compared our "cultural domestication genes" with "food domestication genes" that have been reported as genetic variations in food domestication lines [15]. We first selected 589 genes corresponding to 782 probes and then searched common genes with 540 food domestication genes. We found that 28 genes had been commonly but independently changed in both culturally domesticated chicken lines and food domesticated chicken lines. To test the significance of the representation of overlap genes between the different domestication lines, we computed $p$ values using Fisher's exact test and found no correlation. In other words, the target of selection pressure was not conserved between different breeds. We also checked all selective sweep sites identified by Rubin et al. [15] and also confirmed that the genetic variation loci for cultural and food domestication are independent.

\section{Discussion}

Various breeds of chicken are kept worldwide as pets or for meat, eggs, or other purposes. It is believed that all chicken 
breeds originated from the red junglefowl, one of four species of wild fowl indigenous to Southern China, Southeast Asia, and part of Southwest Asia [7]. Over the course of domestication, the red junglefowl has evolved into a variety of breeds. However, it remains unknown which factors have driven the change from the ancestral species to the currently established chicken breeds.

It is an undeniable fact that human interests strongly influenced the establishment of different chicken breeds during domestication of wild fowl. For example, the bird might have been used in rituals as it was considered by ancient people to be a mysterious animal with a beautiful appearance and song. It is also highly possible that people took advantage of the time-reporting characteristics of the bird, as it crows loudly at dawn, in their daily life. There is also no doubt that domestication focused on providing poultry and eggs, which are readily available culinary items [1-3].

It is worth mentioning that some domesticated Japanese chickens have existed simply for appreciation since the Edo period (1601-1867) and are now considered national treasures. In particular, ancient Japanese people began breeding their favourite Shamo varieties more than 1,000 years ago [11].

The objective of this study was to characterize the ongoing process of chicken domestication by comparative genomic hybridization array analysis, to identify the genetic factors that have contributed to the change from wild fowl to domestic chicken, to identify genes highly specific to chickens for ornamental, fighting, and food purposes, and to determine the sequence of these genes. In recent research, Rubin et al. whole-genome resequencing revealed loci under selection during food chicken domestication, which found little evidence that selection for loss-of-function mutations had a prominent role in this type of domestication (in White Leghorn, Rhode Island Red, Minorca, etc.), but they detected two deletions in coding sequences that they suggested are functionally important.

From our results, category-specific variations were made. We found 782 probes with a fold-change threshold of 2.0 in fighting cocks, long-crowing chickens, and ornamental chickens. To validate the estimation of genomic variations, we amplified 26 of the 782 candidates via PCR based on a primer designed from sequences obtained from the GSC. As a result, 16 of the 26 regions were confirmed to be mutated in the corresponding chickens.

In our analysis of the aCGH results, we estimated the existence of more than 600 probe candidates for genes undergoing human selection pressure in culturally domesticated chickens. We also found that a number of genes diversified in culturally domesticated chickens are different from those diversified in chickens domesticated for food, such as in broilers and layers.

More interestingly, variations in Shamo, bred for cockfighting, were found to be related to muscle development genes, such as $M Y H 1$ and $M Y H 7 B$. Fighting cocks have always been selected for strength, and this selection pressure is responsible for the high number of crosses. Therefore, the Shamo, which was bred for cockfighting, has a muscular, broad body and conspicuous appearance. The Shamo has been bred intensively in Japan, although the tradition of cockfighting is distributed worldwide. Here, we found different specific genes developed for cockfighting between the Shamo and Satsumadori breeds for cockfighting breeds. In general, the Shamo and Satsumadori were bred by ancient humans for different traits, reflecting different regional styles of cockfighting. One style is similar to boxing and the other is more similar to fencing and uses attached blades [42, 43]. These different rules have occurred in different regions of the globe, causing variation of genes developed within breeding chickens for each style of cockfighting.

Additionally, the Koeyoshi, long-crowing chicken breed, has lost many genes that are common in other culturally domesticated chickens. The life expectancy of Koeyoshi with good voices is short, only approximately two years [4]; however, Koeyoshi with weak voices have a much longer life expectancy of up to four years. A strong artificial selection is likely responsible for the shortened life expectancy of Koeyoshi. The specific genes found in this study might have related to its short life. In addition, the results in the small Katsura-chabo revealed that the PIT1 gene was associated with chicken growth traits. Using aCGH, we could find each specific gene acted upon strongly by artificial selection in culturally domesticated chickens. Therefore, these specific genes are highly relevant for various fields of ongoing research in domesticated chickens or for the domestication process to preserve these breeds in the future.

Humans have improved the desirable characteristics of chickens to make use of them in daily life. In the same way, chickens have taken advantage of their surroundings and characteristics and have continued to change in appearance and nature to leave behind offspring that is coexisting with humans.

\section{Conclusions}

We examined the genes that are responsible for aggressiveness and crowing behaviour by utilizing aCGH analysis with six breeds of culturally domesticated chickens representing fighting cocks, long-crowing chickens, and ornamental chickens. From our analysis of the aCGH results, we estimated the existence of 782 probe candidates for genes undergoing human selection pressure in culturally domesticated chickens. Upon comparing a wild variant, Yakei, and the GSC chicken that has been fully sequenced, $10.9 \%$ of genomic regions were found to have been modified. Growth hormonerelated genes known to be modified in food domesticated lines were also genetically modified in long-crowing chickens. We also found that a number of genes diversified in culturally domesticated chickens are different from those diversified in chickens, such as broilers and layers, which have been domesticated for food.

\section{Competing Interests}

The authors declare that there are no competing interests regarding the publication of this paper. 


\section{Acknowledgments}

The authors thank Dr. Masa-aki Yoshida and Ms. Satsuki Takagi of Ochanomizu University for their kind help. Their thanks also go to the Bird Center of Kurume for their red junglefowl samples. This work was supported by Program to Disseminate Tenure Tracking System of the Ministry of Education, Culture, Sports, Science and Technology, the Japanese Government, Grant-in-Aid for Young Scientists (B), and a grant from the KAKENHI (21570241 and 24770002).

\section{References}

[1] E. Isaac, Geography of Domestication, Prentice-Hall, Englewood Cliffs, NJ, USA, 1970.

[2] C. O. Sauer, Agricultural Origins and Dispersals, American Geographical Society, New York, NY, USA, 1952.

[3] P. Smith and C. Daniel, The Chicken Book, The University of Georgia Press, Athens, Georgia, 2000.

[4] T. Komiyama, H. Iwama, N. Osada et al., "Dopamine receptor genes and evolutionary differentiation in the domestication of fighting cocks and long-crowing chickens," PLOS ONE, vol. 9, no. 7, article e101778, 2014.

[5] T. Komiyama, K. Ikeo, and T. Gojobori, "The evolutionary origin of long-crowing chicken: its evolutionary relationship with fighting cocks disclosed by the mtDNA sequence analysis," Gene, vol. 333, pp. 91-99, 2004.

[6] T. Komiyama, K. Ikeo, Y. Tateno, and T. Gojobori, "Japanese domesticated chickens have been derived from Shamo traditional fighting cocks," Molecular Phylogenetics and Evolution, vol. 33, no. 1, pp. 16-21, 2004.

[7] D. Charles, The Variation of Animals and Plants under Domestication, The Johns Hopkins University Press, London, UK, 1998.

[8] F. E. Zeuner, A History of Domesticated Animals, Haper and Row, New York, NY, USA, 1963.

[9] B. West and B.-X. Zhou, "Did chickens go north? New evidence for domestication," Journal of Archaeological Science, vol. 15, no. 5, pp. 515-533, 1988.

[10] M. Tsudzuki, “Japanese native chickens," in The Relationship between Indigenous Animals and Humans(in) APEC Regions, $\mathrm{H}$. L. Chang and Y. C. Huang, Eds., pp. 91-116, The Chinese Society of Animal Science, Tainan, Taiwan, 2003.

[11] T. Komiyama, K. Ikeo, and T. Gojobori, "Where is the origin of the Japanese gamecocks?" Gene, vol. 317, no. 1-2, pp. 195-202, 2003.

[12] W. M. Muir, G. K.-S. Wong, Y. Zhang et al., "Genome-wide assessment of worldwide chicken SNP genetic diversity indicates significant absence of rare alleles in commercial breeds," Proceedings of the National Academy of Sciences of the United States of America, vol. 105, no. 45, pp. 17312-17317, 2008.

[13] M. A. M. Groenen, P. Wahlberg, M. Foglio et al., "A high-density SNP-based linkage map of the chicken genome reveals sequence features correlated with recombination rate," Genome Research, vol. 19, no. 3, pp. 510-519, 2009.

[14] A. Wirén, U. Gunnarsson, L. Andersson, and P. Jensen, "Domestication-related genetic effects on social behavior in chickenseffects of genotype at a major growth quantitative trait locus," Poultry Science, vol. 88, no. 6, pp. 1162-1166, 2009.

[15] C.-J. Rubin, M. C. Zody, J. Eriksson et al., "Whole-genome resequencing reveals loci under selection during chicken domestication," Nature, vol. 464, no. 7288, pp. 587-591, 2010.
[16] C. Berthouly-Salazar, X. Rognon, T. N. Van et al., "Vietnamese chickens: a gate towards Asian genetic diversity," BMC Genetics, vol. 11, article 53, 2010.

[17] H. Sawai, H. L. Kim, K. Kuno et al., "The origin and genetic variation of domestic chickens with special reference to junglefowls Gallus g. gallus and G. varius," PLoS ONE, vol. 5, no. 5, Article ID e10639, 2010.

[18] H. H. D. Kerstens, R. P. M. A. Crooijmans, B. W. Dibbits, A. Vereijken, R. Okimoto, and M. A. M. Groenen, "Structural variation in the chicken genome identified by paired-end next-generation DNA sequencing of reduced representation libraries," BMC Genomics, vol. 12, article 94, 2011.

[19] M. Tixier-Boichard, B. Bed'Hom, and X. Rognon, "Chicken domestication: from archeology to genomics," Comptes Rendus Biologies, vol. 334, no. 3, pp. 197-204, 2011.

[20] I. Tiemann and G. Rehkämper, "Evolutionary pets: offspring numbers reveal speciation process in domesticated chickens," PLoS ONE, vol. 7, no. 8, Article ID e41453, 2012.

[21] Q. Li, N. Wang, Z. Du et al., "Gastrocnemius transcriptome analysis reveals domestication induced gene expression changes between wild and domestic chickens," Genomics, vol. 100, no. 5, pp. 314-319, 2012.

[22] A. C. Rossi, C. Mammucari, C. Argentini, C. Reggiani, and S. Schiaffino, "Two novel/ancient myosins in mammalian skeletal muscles: MYH14/7b and MYH15 are expressed in extraocular muscles and muscle spindles," The Journal of Physiology, vol. 588, no. 2, pp. 353-364, 2010.

[23] L. A. Moore, M. J. Arrizubieta, W. E. Tidyman, L. A. Herman, and E. Bandman, "Analysis of the chicken fast myosin heavy chain family: localization of isoform-specific antibody epitopes and regions of divergence," Journal of Molecular Biology, vol. 225, no. 4, pp. 1143-1151, 1992.

[24] S. Machida, S. Noda, A. Takao, M. Nakazawa, and R. Matsuoka, "Expression of slow skeletal myosin heavy chain 2 gene in Purkinje fiber cells in chick heart," Biology of the Cell, vol. 94, no. 6, pp. 389-399, 2002.

[25] S. Mezey, D. Krivokuca, E. Bálint, A. Adorján, G. Zachar, and A. Csillag, "Postnatal changes in the distribution and density of neuronal nuclei and doublecortin antigens in domestic chicks (Gallus domesticus)," Journal of Comparative Neurology, vol. 520, no. 1, pp. 100-116, 2012.

[26] A. Capes-Davis, O. Tolhurst, J. M. Dunn, and P. L. Jeffrey, "Expression of doublecortin (DCX) and doublecortin-like kinase (DCLK) within the developing chick brain," Developmental Dynamics, vol. 232, no. 2, pp. 457-467, 2005.

[27] J. H. Christiansen, E. G. Coles, V. Robinson, A. Pasini, and D. G. Wilkinson, "Screening from a subtracted embryonic chick hindbrain cDNA library: identification of genes expressed during hindbrain, midbrain and cranial neural crest development," Mechanisms of Development, vol. 102, no. 1-2, pp. 119-133, 2001.

[28] A. J. Hannan, R. C. Henke, G. S. Seeto, A. Capes-Davis, J. Dunn, and P. L. Jeffrey, "Expression of doublecortin correlates with neuronal migration and pattern formation in diverse regions of the developing chick brain," Journal of Neuroscience Research, vol. 55, no. 5, pp. 650-657, 1999.

[29] N. Vargesson, V. Luria, I. Messina, L. Erskine, and E. Laufer, "Expression patterns of Slit and Robo family members during vertebrate limb development," Mechanisms of Development, vol. 106, no. 1-2, pp. 175-180, 2001.

[30] S. Tang, D. Sun, J. Ou, Y. Zhang, G. Xu, and Y. Zhang, "Evaluation of the IGFs (IGF1 and IGF2) genes as candidates for growth, 
body measurement, carcass, and reproduction traits in Beijing You and Silkie chickens," Animal Biotechnology, vol. 21, no. 2, pp. 104-113, 2010.

[31] J. W. Lu, J. P. McMurtry, and C. N. Coon, "Developmental changes of plasma insulin, glucagon, insulin-like growth factors, thyroid hormones, and glucose concentrations in chick embryos and hatched chicks," Poultry Science, vol. 86, no. 4, pp. 673-683, 2007.

[32] G. Wang, B. Yan, X. Deng, C. Li, X. Hu, and N. Li, "Insulinlike growth factor 2 as a candidate gene influencing growth and carcass traits and its bialleleic expression in chicken," Science in China Series C: Life Sciences, vol. 48, no. 2, pp. 187-194, 2005.

[33] L. B. Koski, E. Sasaki, R. D. Roberts, J. Gibson, and R. J. Etches, "Monoalleleic transcription of the insulin-like growth factorII gene (Igf2) in chick embryos," Molecular Reproduction and Development, vol. 56, no. 3, pp. 345-352, 2000.

[34] M. C. Fisher, C. Meyer, G. Garber, and C. N. Dealy, "Role of IGFBP2, IGF-I and IGF-II in regulating long bone growth," Bone, vol. 37, no. 6, pp. 741-750, 2005.

[35] D. C. Darling and P. M. Brickell, "Nucleotide sequence and genomic structure of the chicken insulin-like growth factor-II (IGF-II) coding region," General and Comparative Endocrinology, vol. 102, no. 3, pp. 283-287, 1996.

[36] T. K. Bhattacharya, R. N. Chatterjee, and M. Priyanka, "Polymorphisms of Pit-1 gene and its association with growth traits in chicken," Poultry Science, vol. 91, no. 5, pp. 1057-1064, 2012.

[37] Q. Nie, M. Fang, L. Xie et al., "The PIT1 gene polymorphisms were associated with chicken growth traits," BMC Genetics, vol. 9, article 20, 2008.

[38] R. Jiang, J. Li, L. Qu, H. Li, and N. Yang, "A new single nucleotide polymorphism in the chicken pituitary-specific transcription factor (POU1F1) gene associated with growth rate," Animal Genetics, vol. 35, no. 4, pp. 344-346, 2004.

[39] T. M. Crowley, V. R. Haring, S. Burggraaf, and R. J. Moore, "Application of chicken microarrays for gene expression analysis in other avian species," BMC Genomics, vol. 10, article S3, 2009.

[40] M. Jöngren, J. Westander, D. Nätt, and P. Jensen, "Brain gene expression in relation to fearfulness in female red junglefowl (Gallus gallus)," Genes, Brain and Behavior, vol. 9, no. 7, pp. 751758, 2010.

[41] D. Nätt, C.-J. Rubin, D. Wright et al., "Heritable genome-wide variation of gene expression and promoter methylation between wild and domesticated chickens," BMC Genomics, vol. 13, no. 1, article 59, 2012.

[42] C. Finsterbusch, Cock Fighting All over the World, England Nimrod Press, Alton, UK, 1980.

[43] A. Dundes, The Cockfight, The University of Wisconsin Press, Madison, Wis, USA, 1994. 

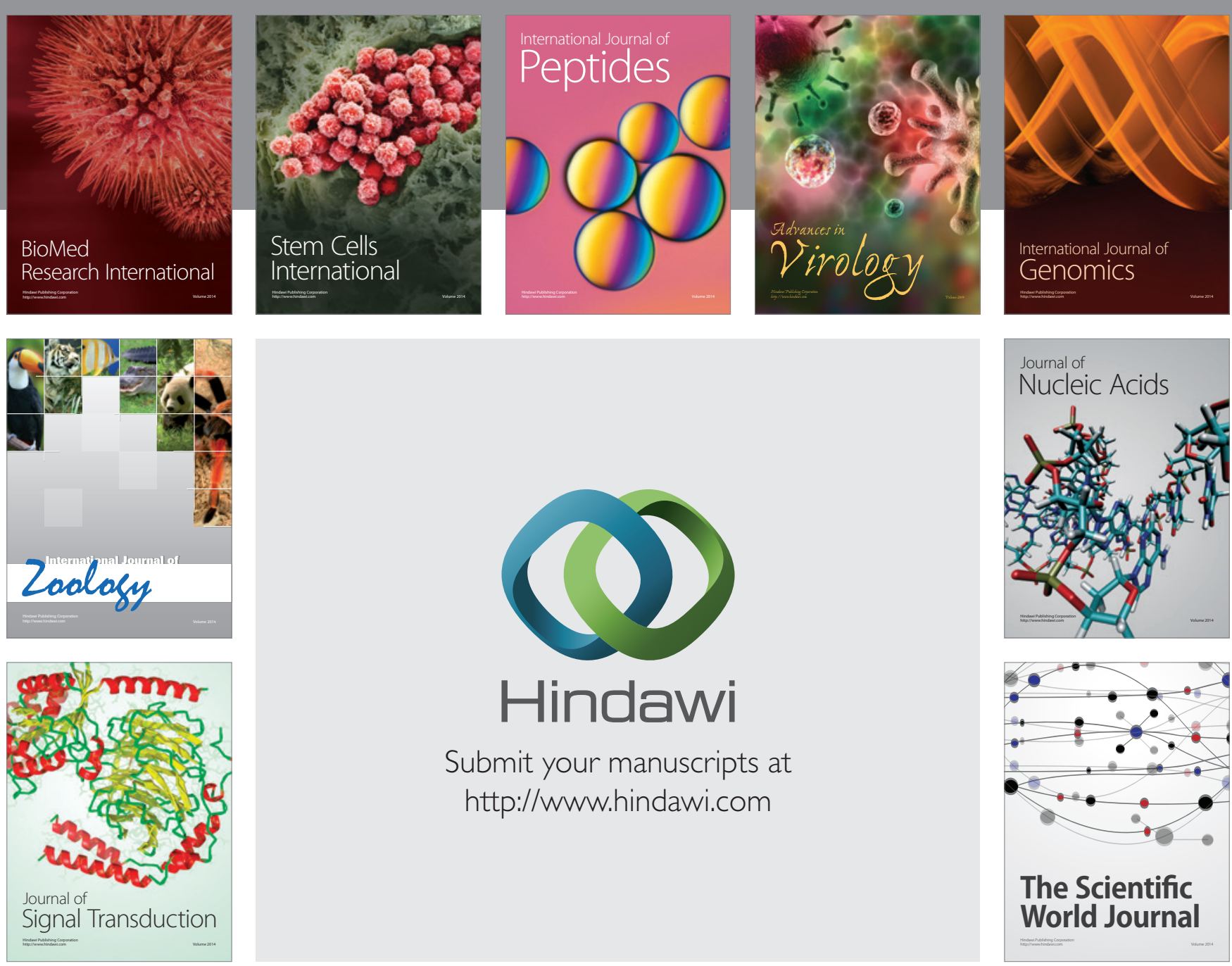

Submit your manuscripts at

http://www.hindawi.com
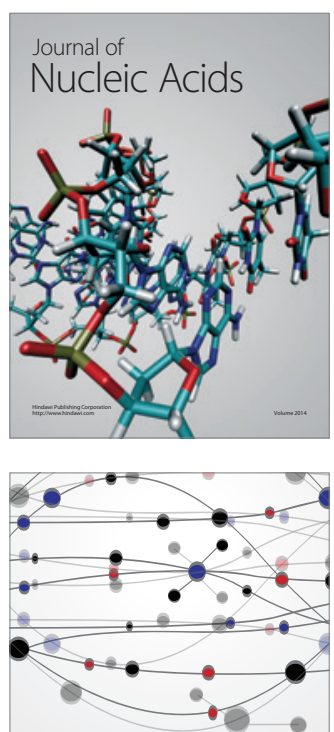

The Scientific World Journal
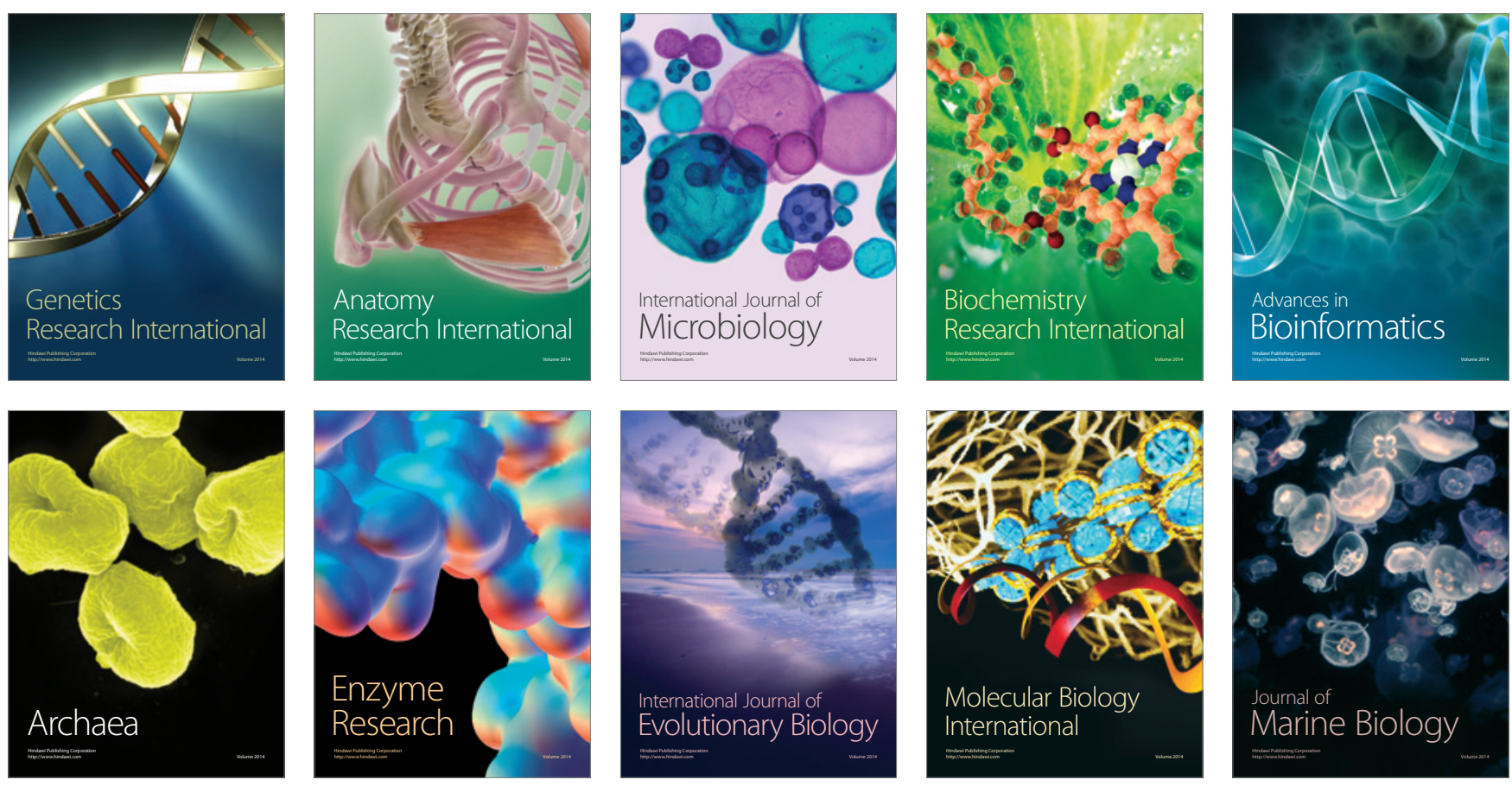